never be dispensed with. In many cases the short posterior retractor is vastly more efficient than the long ones used in Europe. It enables you to bring the vaginal vault within easy reach, and to follow the steps of the operation with much more ease and precision than when one has to work in the depths of a deep hole. Even in cases of fixation I have been able at times to use the short retractor to greater ad. vantage than the long one, and I am so imbued with its value that I would be loth to attempt any of the more serious operations through the vaginal vault without having one at hand. Feeling the want of a self-retaining retractor, that was simple and efficient, I devised the instrument which I now show you. You will observe that it consists of two pieces. The holder which passes under the sacrum and is held firm by the weight of the body and at the extremity of which is a steel pin for holding, and a screw for adjusting, the blade of the retractor at any angle. The retractor has a short handle with notches on the inner aspect and a ring at the end. In adjusting the speculum it is introduced as any other, then the index finger of the left hand is placed on the blade where it curves inward, while the thumb is placed under the free end or screw of the holder. Now, with the finger of the right hand in the ring of the handle, the retractor is guided into position through the slot on the side, while the blade and holder are approximated by pressure between the thumb and finger. Once in position it is easy to secure the desired degree of perineal retraction by increasing the pressure when it locks itself automatically. Now by turning the thumb screw the inclination of the blade may be changed at will. The mechanism is very simple, the movements are easy, the result all that could be desired. Besides the instrument, as a whole, takes up very littie space and can be carried almost as easily as a bivalve speculum.

\section{REMOTE RESULTS OF REMOVAL OF UTERINE APPENDAGES.}

Read in the Section on Obstetrics and Diseases of Women, at the Fortr sixth Aunual Meeting of the American Medical Association, at Baltimore, Md., May 7-10, 1895.

\section{BY E. E. MONTGOMERY, M.D.}

PHILADEIPHIA, PA.

The introduction of the operation for removal of the tubes and ovaries as advocated almost simultaneously by Battey, Tait and Hegar, though upon distinctly different lines, opened up an extensive field for the practice of abdominal surgery. The enthusiasm of their followers necessarily resulted in the practice of the procedure in many cases when it was of doubtful utility. Battey advocated the operation for intolerable dysmenorrhea; Tait for distinctly recognizable pathologic lesions in tubes and ovaries, principally of an inflammatory character; Hegar to produce an artificial menopause in cases of uterine hemorrhage otherwise uncontrollable.

These distinctly defined indications soon became extended, so that pelvic pain of slight degree, whether associated with menstruation or not, has been considered an excuse for the removal of the organs. Ovaries and tubes have been removed in which careful macroscopic investigation has failed to disclose much, if any, evidence of disease.

The experience of over twenty years has afforded opportunity to study the immediate and remote effects of operations which, at least, must have a profound effect upon the mental and physical nature of the individual in the interference with the procreative function.

It is a well recognized law of nature that unused faculties atrophy, so that it is not surprising to find that after castration of the unmarried female, the genital organs become smaller, the vaginal rugæ disappear and the mucous membrane is thinner and paler. In the married or those who subsequently marry, sexual desire becomes quiescent or even disappears, and to some the marital relation is painful and repugnant. Instead of being a willing and sympathetic partner in the act, she passes through the stages of indifference and passive suffering to disgust and distress.

If the condition just mentioned were the only unpleasant symptom, it would be a matter of but little moment. The most marked influence is upon the nervous system. It is generally recognized that the climacteric is a critical period in the life of every woman, one to which she looks forward with anxiety, realizing that hereditary traits and unpleasant phe. nomena are likely then to manifest themselves. If this be true when the woman matures and reaches the period undisturbed, how much more likely is she to suffer when the climacteric is abruptly and artificially induced, without nature having had an opportunity to prepare her forces for the changed relation.

Every operator is familiar with the flushing, vasomotor disturbances not unfrequently affecting the action of every organ of the body. These do not always disappear in a short period as in the natural menopause, but may continue for years, being a constant source of annoyance and discomfort. While it is true that many patients recover an appearance of good health who were previously great sufferers, in many this improvement will be found to be but tem. porary. Frequent attacks of neuralgia or neurasthenic pain in both ovarian regions as intense as prior to operation, in the uterus, in the intestines, the bladder, or the rectum; insomnia, restlessness and irritability of temper are not uncommon, Even if the individual may have had no desire for offepring, the assurance that motherhood is denied her frequently leads to intense longing for a child. When, however, she has been desirous for children and the possibility is precluded by an operation, the declining sexual appetite not unfrequently leads to a profound melancholy in which she feels life without solace or comfort.

Changes in pigmentation have been observed and it has been asserted that through meustruation certain material is eliminated which in its cessation is retained, producing splotches and discolorations of the skin, or the profound nervous manifestations.

The mental and nervous phenomena may be actuated or aggravated by the sequelæ of the surgical procedures, such as fistulæ, ventral herniæ, painful cicatrices, adhesions of intestines to the uterus, to the stumps, and to the bladder; cellular exudation, infection of ligatures, and the formation of abscess, immediately following the operation or years later.

A case recently came under my observation where, over four years after castration for bleeding fibroid, an abscess formed, which opened in the upper part of the cicatrix. An incision disclosed a large loop of silk in the abscess cavity.

Leucorrhea and irregular profuse uterine hemor. 
rhage not unfrequently follow the removal of both ovaries. Such an array of unpleasant phenomena, associated with the necessary mortality of the procedure when carefully and conscientiously done, should cause the surgeon to hesitate and weigh the condition of each case carefully before resorting to surgical procedure.

I would by no means wish to be understood as denying the necessity and wisdom of operative procedure in necessary cases, but would demand that careful study of the case should determine that the determined procedure was the necessary course for relief.

A careful survey of the immediate and remote influences of pelvic surgery justifies the following conclusions:

1. No mutilation or sacrificial operation should be done, where there is a reasonable probability of relieving the inflammatory condition through vaginal incision and drainage.

2. Efforts should be made to preserve portions of an ovary and a tube through resection, where partially diseased.

3 . Where the ovaries and tubes are diseased, to such a degree as to require their complete removal, the patient is less likely to suffer from profound nervous phenomena if the operation be associated with hysterectomy.

4. Castration should be done for neuroses, only after it has been demonstrated by the experience of capable neurologists that the operation is the dernier ressort.

$$
\text { Drscussion. }
$$

Dr. Henry P. Newman, of Chicago-said the subject under discussion was one of vital interest not only to the operator but decidedly so to the patient. He had never seen a case in which removal of the uterine appendages produced insanity or an outward physical change in the patient, nor had he seen it result in any sexual deterioration to any great extent. In some instances, possibly that had been complained of. He expressed the opinion that before the operation is performed, its possible ill results should be carefully placed before the patient. Furthermore, it should only be performed for actual structural changes in the appendages, and not for mere pain.

DR. M. B. WARD, of Topeka, Kan.-said that where healthy ovaries are removed in young women, very marked nervous symptoms are produced-indeed, so marked that we ought never to do the operation if we can avoid it. He has never seen insanity result from it, however, nor a loss of the sexual appetite. The operation is sometimes followed by a very troublesome leucorrhea. In all cases it is well to postpone the operation as long as possible. Nervous and hysterical patients have greatly improved after the operation.

Dr. Rufus B. HaLl, of Cincinnati-had frequently seen patients suffer mental depression following operations for removal of diseased appendages. With one exception he had never seen insanity follow the operation. This exception was a woman, two of whose sisters had previously died in an insane hospital, and who showed a strong history of hereditary insanity. She died some time after the operation had been performed. There was a large suppurating ovary, and the woman had had gonorrhea. He does not operate for reflex symptoms. Accumulation of fat usually occurs after the operation, this disappearing, however, at the menopause. He has never seen a growth of hair following celiotomy. So far as blunting of the sexual appetite is concerned, he had seen a few instances where this feeling was blunted. In no instance had it entirely disappeared.

DR. G. BETTON MASSEY, of Philadelphia-remarked that his experience on this subject was possibly somewhat peculiar, in view of the fact that the cases he had seen had been operated upon by other men, and his experience fully corroborates the large number of instances mentioned by Dr. Montgomery, of physical and nervous disorders that follow the removal of the ovaries. In one ease $a$ form of melancholia undoubtedly resulted from the operation. In many cases, after the removal of the ovaries in young girls, their moral nature is greatly changed; the sexual feeling is not extinguished, but is largely limited by the operation. He has never seen an extra growth of hair on the face or elsewhere result from the operation.

DR. HowarD A. KeLLY, of Baltimore-had encountered six or eight cases of insanity after operation, one case after an abdominal operation, and one after curettement. All of the abdominal cases got well. When a woman asks him what bodily changes will follow the operation he tells her that she will get stouter and recover her health. The possible loss of sexual power does not militate against the performance of the operation, because these patients are usually in such a condition that they have not enjoyed sexual intercourse for years. On the contrary, the operation often restores family relations which have been impossible for years.

\section{TREATMENT OF CONTRACTIONS OR STENOSIS} OF THE UTERINE CANAL.

Read in the Section on Obstetrics and Diseases of Women, at the Fortysixth Annual Meeting of the American Medical Association. at Baltimore. Md., May $7-10,1895$.

BY WILLTAM A. B. SELLMAN, M.D.

PROFESSOR OF OBSTETRICS AND DISEASES OF WOMEN, BALTIMORE UNIVERSITY, BALTIMORE, MD.

Contracted condition of the uterine canal has been treated by various methods. The slitting up of the cervix is a very unsatisfactory operation, as well as a dangerous one. The enlargement of the canal by means of the sharp curette is uncertain in its results, as the instrument merely scrapes furrows in the tissues and the part soon returns to its previous small caliber. I have attempted to obviate this by imparting a circular motion to the instrument during the operation and, by this means, reaming out the dense tissue at the point of contraction.

Hundreds, yes, thousands of women suffer from dysmenorrhea on account of the uterine canal being contracted at some point. The condition may be acquired or congenital. After amputation of the neck of the uterus, the external os frequently contracts to such an extent that we fail to pass our smallest probe. I intend in this paper to speak more definitely as to the stenosed condition that we find existing at the internal os. These contractions are generally formed of tissue of a denser nature than normal mucous membraue and many times it is of a decidedly cicatricial character. This density of the tissue and this cicatricial character is frequently the cause of the displacement of the organ that we find existing in many of these cases. The fundus of the uterus is pulled over one way or the other, and after the caliber of the canal has been increased we find that the displacement has also been corrected.

I desire at this time to call your attention to a new instrument to remove this condition of stenosis. I call it my reamer.

This reamer is intended to be used to take the place of the slitting up operation and also to supersede the use of the curette. Dysmenorrhea persisting on account of a narrow and, at times, an almost impervious condition of the uterine canal, or due perhaps to the existence of a ring of dense cicatricial tissue at the internal os, which dams back the flow of blood or secretions - these call for the use of the reamer. Rapid dilatation in many cases gives but temporary relief, as the parts return to their previous condition soon after the stretching operation has been performed. The dilator does not remove the dense tissue; it only lacerates it. The curette merely scrapes furrows in the tissue and the contraction remains. 